\title{
Effects of Flexibility and Suspension Configuration of Main Shaft on Dynamic Characteristics of Wind Turbine Drivetrain
}

\author{
Jianjun Tan ${ }^{1}$, Caichao Zhu ${ }^{1 *}$, Chaosheng Song ${ }^{1}$, Huali Han ${ }^{2}$ and Yao Li ${ }^{1}$
}

\begin{abstract}
The current research of wind turbine drivetrain is mainly concentrated in dynamic characteristics of gearbox with a specific suspension of main shaft, such as one-point and two-point suspension. However, little attention is paid to the effects of these suspension configurations on the dynamic responses of wind turbine gearbox. This paper investigates the influences of suspension configurations of main shaft on the dynamic characteristics of drivetrain. For evaluating the dynamic behaviors of drivetrain with multi-stage transmission system more realistically, a dynamic modeling approach of drivetrain is proposed based on Timoshenko beam theory and Lagrange's equation. Considering the flexibility and different suspension configurations of main shaft, time-varying mesh stiffness excitation, time-varying transmission error excitation and gravity excitation, etc., a three-dimensional dynamic model of drivetrain is developed, and the dynamic responses of drivetrain are investigated. Results show that with the one-point suspension of main shaft, the resonance frequencies in gearbox, especially at the low-speed stage, obviously shift to the higher frequency range compared to the gearbox without main shaft, but this trend could be inversed by increasing main shaft length. Meanwhile, the loads in main shaft, main shaft bearing and carrier bearing are greatly sensitive to the main shaft length. Hence, the load sharing is further disrupted by main shaft, but this effect could be alleviated by larger load torque. Comparing to the one-point suspension of main shaft, there occurs the obvious load reduction at the low-speed stage with two-point suspension of main shaft. However, those advantages greatly depend on the distance between two main bearings, and come at the expense of increased load in upwind main shaft unit and the corresponding main bearing. Finally, a wind field test is conducted to verify the proposed drivetrain model. This study develops a numerical model of drivetrain which is able to evaluate the effects of different suspension configurations of main shaft on gearbox.
\end{abstract}

Keywords: Wind turbine drivetrain, Flexible shafts, Suspension configuration, Dynamic responses, Experimental study

\section{Introduction}

Wind turbine drivetrain is a typical example of mechanical transmission system, which has complicated structure connection and kinematic relation. As a connection between impeller and gearbox in drivetrain, main shaft itself was an additional load source that affected the internal response of gearbox [1], and it was also an important

\footnotetext{
*Correspondence: cczhu@cqu.edu.com

${ }^{1}$ The State Key Laboratory of Mechanical Transmissions, Chongqing University, Chongqing 400044, China

Full list of author information is available at the end of the article
}

structural factor to influence the dynamic responses in gearbox due to its different suspension configurations [2]. Therefore, it is essential to develop a dynamic model of drivetrain considering the effects of main shaft length and different suspension configurations of main shaft to investigate the dynamic characteristics of drivetrain for further structure optimization and reliability design.

Recently, there have been extensive studies on the dynamics of wind turbine drivetrain. Helsen et al. [3, 4] proposed a model of flexible multibody for the megawatt level wind turbine and analyzed the effects of drivetrain unit flexibility on the dynamic characteristics. 
Peeters et al. [5, 6] presented three types of multibody dynamic wind turbine model to compare the difference of dynamic responses. Considering the bearing clearance, gravity, variable input load and main shaft, Guo et al. [7] established a model of wind turbine drivetrain by SIMPACK and analyzed the load distribution on the gear teeth and load sharing of planetary gear stage. A fullscale wind turbine model including main shaft was established to compare the dynamic behaviors of drivetrain with different structure abstraction of nacelle testing [8]. Meanwhile, Guo et al. [1] also provided the recommendations for the minimum model fidelities of wind turbine drivetrain where the flexibility of main shaft was considered. With the flexibility of main shaft, Chen et al. $[9,10]$ analyzed the potential resonance points of wind turbine drivetrain according to Campbell analysis, modal energy distribution and order frequency sweep. Zhang et al. [11] built a multibody dynamic model considering three-point suspension for wind turbine drivetrain and analyzed the potential resonance which agreed well with the experiment. However, little investigation was carried out to compare the effects of suspension configuration of main shaft on the dynamic responses of drivetrain for further structure optimization. Meanwhile, there is a non-negligible issue that with the increase of model complexity, the computational efficiency of these models [3-11] would decrease even if it has a higher accuracy. Hence, the lumped parameter method was another solution that was favored by scholars, and its availability was verified by finite element [12] and experiment [13].

Using the lumped parameter method, many dynamic models of gearbox, including planetary gear stage and parallel gear stage, are proposed, but only two translational, one rotational and one axial degrees of freedom (DOFs) for each component are considered in these models. Shi et al. [14] built a torsional dynamic model of gearbox to investigate the system responses. Zhao et al. [15] investigated the dynamic characteristics of gearbox considering the variable input torque. Srikanth et al. [16] investigated the effects of stochastic aerodynamic load on the dynamic behaviors of wind turbine drivetrain. Wei et al. [17] established a multi-stage gear transmission system to investigate the effects of uncertain parameter due to uncertainties in geometric and material properties of wind turbine gearbox. Zhu et al. [18, 19] built a coupled nonlinear dynamic model to investigate the dynamic responses of wind turbine gearbox considering the flexible pin. Zhai et al. [20] studied the dynamic mesh forces in the wind turbine gearbox considering the assembly errors of carrier. However, the previous studies [14-20] on the gearbox dynamics are very limited and mainly focus on the dynamic characteristics of gearbox ignoring the coupled effects of main shaft. Little attention is paid to discuss the dynamics of drivetrain. Guo et al. [1, $2,21]$ indicated that the flexibility and suspension configuration of main shaft could greatly affect the gearbox's internal response, and their models considered six DOFs for each component.

The main objective of this paper is to propose a dynamic modeling approach and to develop a threedimensional dynamic model of drivetrain. Then, the ode solver is applied to solve the dynamic model of drivetrain, and the dynamic responses of drivetrain are investigated. Firstly, the dynamic mesh forces are analyzed to study the influences caused by different main shaft length. Secondly, the comparisons of different suspension configurations of main shaft are investigated, meanwhile, the load sharing and carrier bearing load are analyzed. Finally, the experiment is carried out to verify the proposed model.

\section{Transmission Principle for Wind Turbine Drivetrain}

A typical wind turbine drivetrain with three-point suspension is shown in Figure 1a [22]. Three supporting points consist of one main shaft bearing and two torque arms. As shown in Figure 1b, the mechanical system of gearbox can be divided into three transmission stages. The 1st planetary gear stage contains three planet gears, sun gear, ring gear and carrier. The 2nd parallel gear stage includes Gear 1 and Gear 2 fixed on the shaft 1 and shaft 2 , respectively. The 3 rd parallel gear stage contains Gear 3 and Gear 4, which are attached to shaft 2 and shaft 3, respectively. The generator (not shown) is connected to shaft 3 by coupler.

The partial structure parameters of drivetrain for a 2 MW doubly-fed wind turbine are shown in Table 1 . The other parameters, including the bearing stiffness and geometrical parameters of parallel gear shafts, are detailed in Refs. [11, 23].

\section{Dynamic Model}

According to the structure diagram of a wind turbine drivetrain shown in Figure 1, a three-dimensional dynamic model of drivetrain is proposed with proper simplification. Each gear or flexible shaft node considers six DOFs. The total number of DOFs for a drivetrain system is $(6(N+3)+6 P+1)$, where $N$ and $P$ denote the number of planets and flexible shaft nodes, respectively.

\subsection{Shaft Element Model}

In Figure 2, the shafts, including the main shaft and parallel stage shafts (shaft 1 , shaft 2 and shaft 3 ), can be divided into shaft segments from prototype to type A based on the Timoshenko beam theory [24, 25]. Each node has six DOFs. For avoiding massive computation, the shaft element model is further simplified into type $B$ and only keeps 


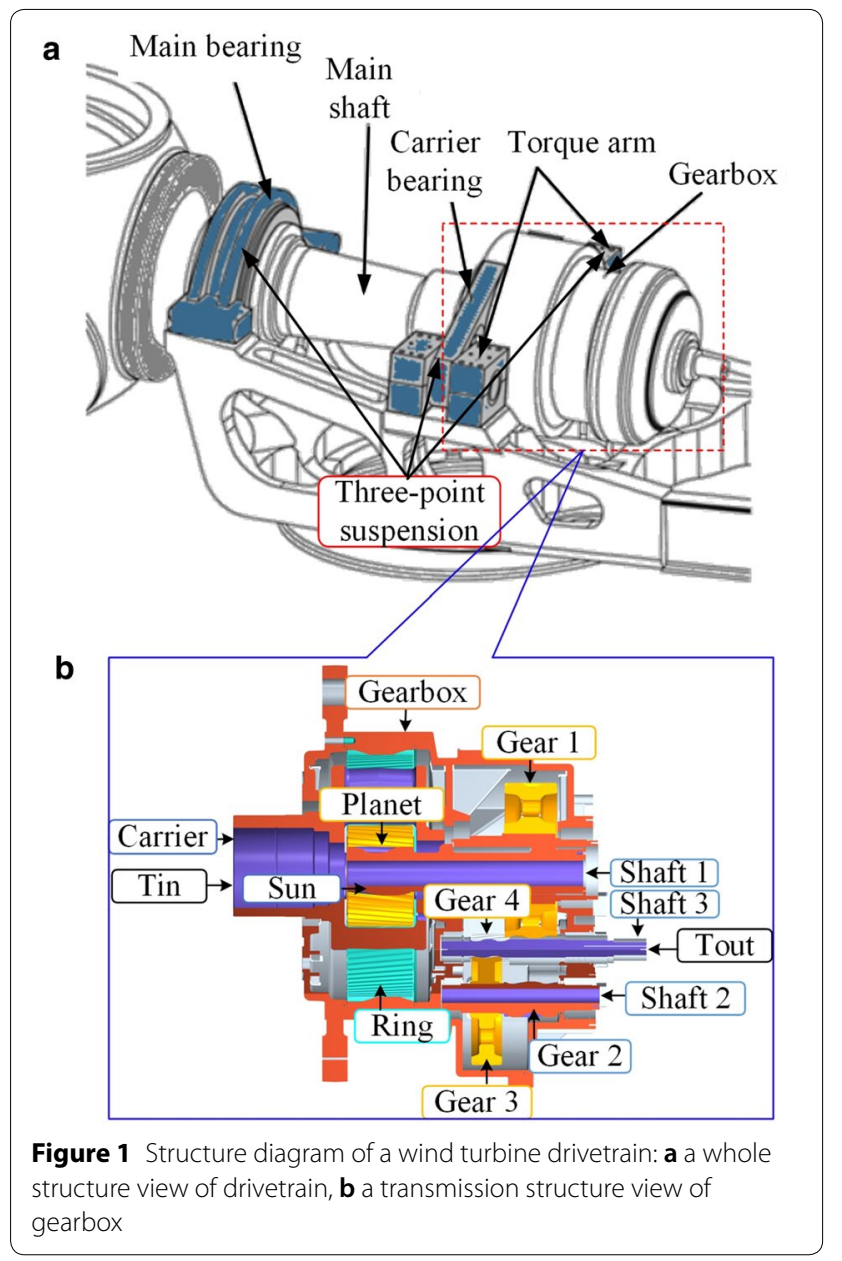

main nodes, which contains the position of bearings and gears. The displacement vector of the iith shaft element with two nodes can be given by

Table 1 Structure parameters

\begin{tabular}{lllll}
\hline Planetary gear stage & Ring & Sun & Planet & Carrier \\
\hline Number of teeth & 96 & 21 & 37 & - \\
Modulus $(\mathrm{mm})$ & 15 & & & - \\
Pressure angle $\left(^{\circ}\right)$ & 25 & & & - \\
Helical angle $\left(^{\circ}\right)$ & 8 & & & - \\
Mesh stiffness $(\mathrm{N} / \mathrm{m})$ & $\bar{k}_{\text {spi }}=6.7 \times 10^{9}$ & $\bar{k}_{\text {rpi }}=8.4 \times 10^{9}$ \\
Parallel gear stage & Gear $1 \quad$ Gear 2 & Gear 3 & Gear 4 \\
Number of teeth & 97 & 23 & 103 & 21 \\
Modulus $(\mathrm{mm})$ & 11 & & 8 & \\
Pressure angle $\left({ }^{\circ}\right)$ & 20 & & & \\
Helical angle $\left(^{\circ}\right)$ & 20 & & & \\
Mesh stiffness $(\mathrm{N} / \mathrm{m})$ & $\bar{k}_{\mathrm{G} 1 \mathrm{G} 2}=6.0 \times 10^{9}$ & $\bar{k}_{\mathrm{G} 3 \mathrm{G} 4}=3.1 \times 10^{9}$ \\
Main shaft length $(\mathrm{m})$ & 2.07 & & & \\
Main shaft diameter $(\mathrm{m})$ & 0.7 & & & \\
\hline
\end{tabular}

$$
\begin{aligned}
\boldsymbol{X}_{i i, i i+1}^{\mathrm{s}}= & {\left[\left(\boldsymbol{X}_{i i}^{s}\right)^{\mathrm{T}},\left(\boldsymbol{X}_{i i+1}^{s}\right)^{\mathrm{T}}\right]^{\mathrm{T}} } \\
= & \left(x_{i i}, y_{i i}, z_{i i}, \theta_{i i}^{x}, \theta_{i i}^{y}, \theta_{i i}^{z}, x_{i i+1},\right. \\
& \left.y_{i i+1}, z_{i i+1}, \theta_{i i+1}^{x}, \theta_{i i+1}^{y}, \theta_{i i+1}^{z}\right)^{\mathrm{T}} .
\end{aligned}
$$

The $12 \times 12$ order form of Timoshenko beam element stiffness matrix can be written by Eq. (2). Similarly, the mass matrix $\boldsymbol{M}_{i i, i i+1}^{\mathrm{s}}$ of the iith shaft element can be acquired in Refs. [24, 25].

In Eqs. (2) and (3), $E$ is elastic modulus of materials, $I$ is cross-sectional moment of inertia. $A$ and $L$ are the crosssectional area and length of the iith shaft element, respectively. $K^{\prime}$ is the shear coefficient of the circular section. $G$ is the shear modulus and $J$ represents torsional moment of inertia. As a typically heavy component in wind turbine, the weight of flexible shaft should be considered, especially the main shaft. Thus, the gravity excitation $F_{i i}^{\mathrm{g}}$ caused by gravity of the iith shaft element can be deduced in Eq. (4).

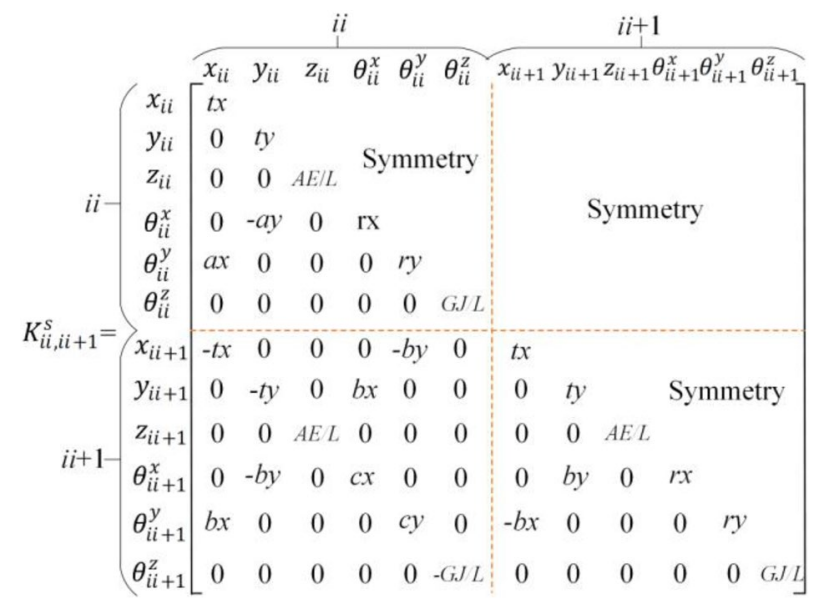

where

$$
\begin{aligned}
& \left\{\begin{array}{l}
t x=t y=\frac{12 E I}{L^{3}(1+\phi)} \\
a x=a y=6 L \frac{12 E I}{L^{3}(1+\phi)} \\
b x=b y=6 L \frac{12 E I}{L^{3}(1+\phi)} \\
r x=r y=L^{2}(4+\phi) \frac{12 E I}{L^{3}(1+\phi)} \\
c x=c y=L^{2}(2-\phi) \frac{12 E I}{L^{3}(1+\phi)} \\
\phi=\frac{12 E I}{K^{\prime} G A L^{2}}
\end{array}\right. \\
& F_{i i}^{\mathrm{g}}=\int_{0}^{L}-A \rho g N_{\mathrm{w}}^{\mathrm{T}} \mathrm{d} s
\end{aligned}
$$



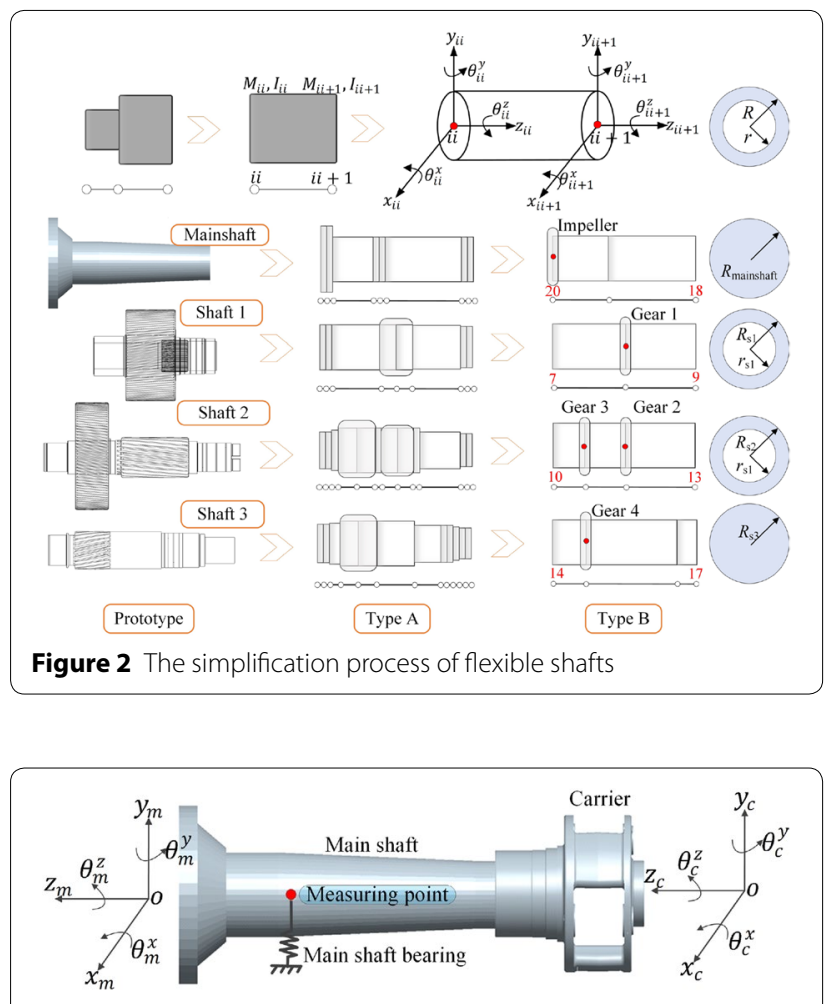

Figure 3 Structure diagram of main shaft and carrier

where $\rho$ is the material density, $g$ denotes the gravitational acceleration and $N_{\mathrm{w}}$ is the interpolation function along gravitational direction [25]. $s$ represents the non-dimensional distance from the section in the $i i$ th shaft element.

The equation of motion of the iith shaft element can be written as

$$
M_{i i, i i+1}^{\mathrm{s}} \ddot{X}_{i i, i i+1}^{\mathrm{s}}+C_{i i, i i+1}^{\mathrm{s}} \dot{X}_{i i, i i+1}^{\mathrm{s}}+K_{i i, i i+1}^{\mathrm{s}} X_{i i, i i+1}^{\mathrm{s}}=F_{i i, i i+1}^{\mathrm{ex}},
$$

where $\boldsymbol{F}_{i i, i i+1}^{\mathrm{ex}}$ is the applied load matrix, including the force $\boldsymbol{F}_{i i}^{\mathrm{g}}$ and applied torque load, and $\boldsymbol{C}_{i i, i i+1}^{\mathrm{S}}$ is the material damping matrix.

\subsection{Connection Relationship between Main Shaft and Carrier}

According to the simplified structure of main shaft shown in Figure 2 and the connection relationship between main shaft and carrier presented in Figure 3, the elastic deformation $\Delta_{18 c}$ between the main shaft (node 18) and carrier can be calculated.

$$
\Delta_{18 c}=\left[\begin{array}{c}
\Delta x_{18 c} \\
\Delta y_{18 c} \\
\Delta z_{18 c} \\
\Delta \theta_{18 c}^{x} \\
\Delta \theta_{18 c}^{y} \\
\Delta \theta_{18 c}^{z}
\end{array}\right]=\left[\begin{array}{c}
x_{c-a}-x_{18} \\
y_{c-a}-y_{18} \\
z_{c-a}-z_{18} \\
\theta_{c-a}^{x}-\theta_{18}^{x} \\
\theta_{c-a}^{y}-\theta_{18}^{y} \\
\theta_{c-a}^{z}-\theta_{18}^{z}
\end{array}\right],
$$

where $\quad \boldsymbol{X}_{c-a}=\left(x_{c-a}, y_{c-a}, z_{c-a}, \theta_{c-a}^{x}, \theta_{c-a}^{y}, \theta_{c-a}^{z}\right)^{\mathrm{T}}$ denotes the vibration displacement vector of carrier and $\boldsymbol{X}_{18}=\left(x_{18}, y_{18}, z_{18}, \theta_{18}^{x}, \theta_{18}^{y}, \theta_{18}^{z}\right)^{\mathrm{T}}$ represents the vibration displacement vector of main shaft at node 18 with respect to absolute coordinate system $o x_{m} y_{m} z_{m}$, as shown in Figure 3. The $x, y$ and $z$ represent the horizontal, vertical and axial directions in this paper, respectively.

A transformation matrix $\boldsymbol{T}$ is adopted to transform vibration displacements of carrier from moving coordinate system $o x_{c} y_{c} z_{c}$ to absolute coordinate system $o x_{m} y_{m} z_{m}$.

$$
\begin{aligned}
& \boldsymbol{X}_{c-\mathrm{a}}=\boldsymbol{T} \boldsymbol{X}_{c}, \\
& \boldsymbol{T}=\left[\begin{array}{cccccc}
\cos \theta_{c} & -\sin \theta_{c} & \cdots & \ldots & \cdots & 0 \\
\sin \theta_{c} & \cos \theta_{c} & \cdots & \cdots & 0 & \vdots \\
\vdots & \vdots & 1 & 0 & \vdots & \vdots \\
\vdots & \vdots & 0 & \cos \theta_{c} & -\sin \theta_{c} & \vdots \\
\vdots & 0 & \cdots & \sin \theta_{c} & \cos \theta_{c} & \vdots \\
0 & \cdots & \cdots & \cdots & \cdots & 1
\end{array}\right],
\end{aligned}
$$

where $\boldsymbol{X}_{c}=\left(x_{c}, y_{c}, z_{c}, \theta_{c}^{x}, \theta_{c}^{y}, \theta_{c}^{z}\right)^{\mathrm{T}}$ is the vibration displacement vector of carrier measured in $0 x_{c} y_{c} z_{c}$. $\theta_{c}$ denotes the rotation angle of carrier.

\subsection{Gear Mesh Model}

The mechanical transmission system of the gearbox is divided into one planetary gear stage and two parallel gear stages. Only one torsional DOF for generator is considered. The brake disc and coupler are taken as a coupled mass at node 17 for simplification.

The dynamic models of planetary gear stage and parallel gear stage are shown in Figures 4 and 5, respectively. In these dynamic models, the components, including sun gear $(s)$, ring gear $(r)$, carrier $(c)$, planet gear $(p)$, Gear 1 (G1), Gear 2 (G2), Gear 3 (G3) and Gear 4 (G4), are modeled as the rigid bodies. The mass matrix is in the form of $\boldsymbol{M}_{l(i, u)}=\operatorname{diag}\left(m_{l(i, u)}, m_{l(i, u)}, m_{l(i, u)}, I_{l(i, u)}^{x}, I_{l(i, u)}^{y}, I_{l(i, u)}^{z}\right)$, in which $l=s, r, c, i=1, \ldots, N, u=\mathrm{G} 1, \mathrm{G} 2, \mathrm{G} 3$ and G4, respectively. The moment of inertia of generator is $I_{\text {gen }}^{z}$.

In Figure 4, three kinds of coordinate systems are utilized in the model. The absolute coordinate system OXYZ is fixed on the central member $l(l=s, r, c)$. Both moving coordinate systems $o x_{i} y_{l} z_{l}$ and $o x_{i} y_{i} z_{i}(i=1, \ldots, N, N$ is the number of planets) are fixed on the carrier center and planet gear center, respectively, rotating with carrier angular velocity $w_{c}$. The vibration displacement vector of the component $l$ or $i$ is $\boldsymbol{X}_{l(i)}=\left(x_{l(i)}, y_{l(i)}, z_{l(i)}, \theta_{l(i)}^{x}, \theta_{l(i)}^{y}, \theta_{l(i)}^{z}\right)^{\mathrm{T}}$, 


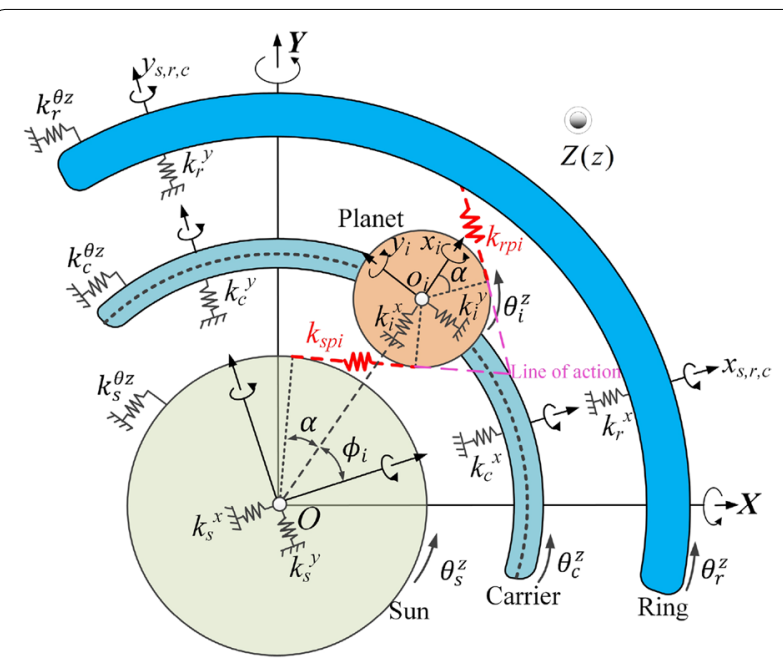

Figure 4 Lumped parameter model of planetary gear stage

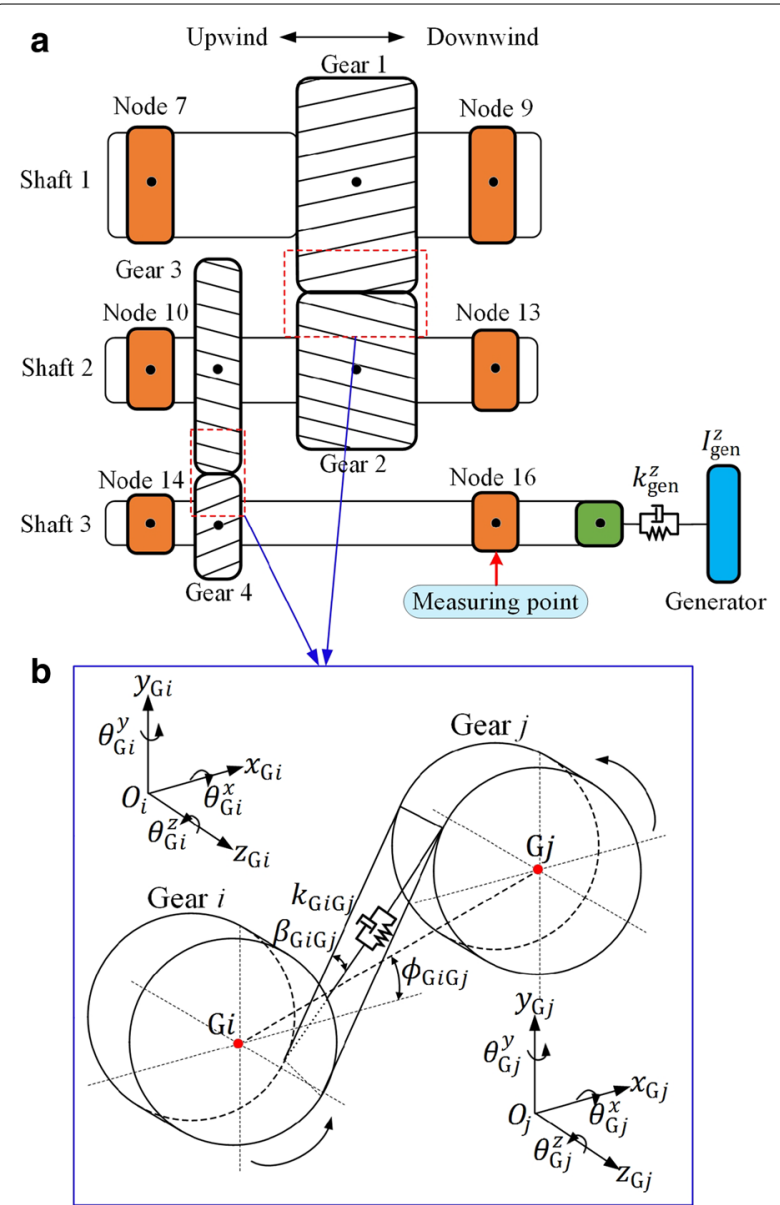

Figure 5 Lumped parameter model of parallel gear stage: a a whole structure view of parallel gear stages and $\mathbf{b}$ a three-dimensional model of a mesh and the corresponding bearing stiffness matrix is in form of $\boldsymbol{K} \boldsymbol{b}_{l(i)}=\operatorname{diag}\left(k_{l(i)}^{x}, k_{l(i)}^{y}, k_{l(i)}^{z}, k_{l(i)}^{\theta x}, k_{l(i)}^{\theta y}, k_{l(i)}^{\theta z}\right), \quad$ in $\quad$ which $k_{l(i)}^{x}, k_{l(i)}^{y}, k_{l(i)}^{z}\left(k_{l(i)}^{\theta x}, k_{l(i)}^{\theta y}, k_{l(i)}^{\theta z}\right)$ denote the radial (torsional) bearing stiffness of the component $l(i)$ along $x$-, $y$ - and $z$-direction, respectively.

The mesh deflections of the $i$ th sun-planet and the $i$ th ring-planet along the mesh line of action can be equivalent to $\Delta_{\gamma}$.

$$
\begin{aligned}
\Delta_{\gamma} & =\left( \pm \sin \varphi_{\gamma} \cos \beta_{\mathrm{b}},-\cos \varphi_{\gamma} \cos \beta_{\mathrm{b}}, \mp \sin \beta_{\mathrm{b}}\right. \\
& \mp r_{\mathrm{m} \tau} \sin \phi_{i} \sin \beta_{\mathrm{b}}, \pm r_{\mathrm{m} \tau} \cos \phi_{i} \sin \beta_{\mathrm{b}},-r_{\mathrm{b} \tau} \cos \beta_{\mathrm{b}}, \\
& \mp \sin \alpha \cos \beta_{\mathrm{b}}, \cos \alpha \cos \beta_{\mathrm{b}}, \pm \sin \beta_{\mathrm{b}}, 0, \\
& \left.r_{\mathrm{m} i} \sin \beta_{\mathrm{b}} / \cos \alpha, \mp r_{\mathrm{b} i} \cos \beta_{\mathrm{b}}\right) \cdot\left(\boldsymbol{X}_{\tau}^{\mathrm{T}}, \boldsymbol{X}_{i}^{\mathrm{T}}\right)^{\mathrm{T}}+e_{\gamma},
\end{aligned}
$$

where $e_{\gamma}$ is the static transmission error (STE) of the mesh $\gamma$, and $k_{\gamma}$ is the mesh stiffness of the mesh $\gamma$. For the symbol ' \pm ', the superscript is used when $\gamma=s p i$, and the subscript is available as $\gamma=r p i$. When $\gamma=s p i$, $\tau=s$ as well as $\gamma=r p i, \tau=r . \varphi_{\gamma}=\alpha \pm \phi_{i}, \alpha$ is the pressure angle, $\phi_{i}$ is the position angle of planet $i$ in $o_{i} x_{l} z_{l} z_{l}$ $\phi_{i}=2 \pi(i-1) / N(i=1, \ldots, N) . \beta_{\mathrm{b}}$ denotes the helical angle. $r_{\mathrm{m} \tau}\left(r_{\mathrm{m} i}\right)$ and $r_{\mathrm{b} \tau}\left(r_{\mathrm{b} i}\right)$ are the reference circle radius and base circle radius of the component $\tau(i)$, respectively.

Similarly, the coupled relationship of parallel gear stages is shown in Figure 5 . The displacement vector $\boldsymbol{X}_{u}=\left(x_{u}, y_{u}, z_{u}, \theta_{u}^{x}, \theta_{u}^{y}, \theta_{u}^{z}\right)^{\mathrm{T}}$ is assigned to the component $u$ in the absolute coordinate system $o x_{u} y_{u} z_{u}$, as shown in Figure 5b. The bearing stiffness matrix is $\boldsymbol{K} \boldsymbol{b}_{H}=\operatorname{diag}\left(k_{H}^{x}, k_{H}^{y}, k_{H}^{z}, k_{H}^{\theta x}, k_{H}^{\theta y}, k_{H}^{\theta z}\right)$ where $k_{H}^{x}, k_{H}^{y}, k_{H}^{z}$ $\left(k_{H}^{\theta x}, k_{H}^{\theta y}, k_{H}^{\theta z}\right)$ represent the radial (torsional) bearing stiffness at node $H$ along $x$-, $y$ - and $z$-direction, respectively.

The mesh deflection corresponding to the Gear 1-Gear 2 and Gear 3-Gear 4 meshes along the mesh line of action direction can be expressed by Eq. (9):

$$
\begin{aligned}
\Delta_{\xi \eta} & =\left(\mp \sin \varphi_{\xi} \cos \beta_{\xi},-\cos \varphi_{\xi} \cos \beta_{\xi}, \sin \beta_{\xi}\right. \\
& \mp r_{\mathrm{m} \xi} \sin \phi_{\xi \eta} \sin \beta_{\xi}, \pm r_{\mathrm{m} \xi} \cos \phi_{\xi \eta} \sin \beta_{\xi} \\
& \pm r_{\mathrm{b} \xi} \cos \beta_{\xi}, \pm \sin \varphi_{\xi} \cos \beta_{\xi}, \cos \varphi_{\xi} \cos \beta_{\xi} \\
& -\sin \beta_{\xi}, \mp r_{\mathrm{m} \eta} \sin \phi_{\xi \eta} \sin \beta_{\xi}, \pm r_{\mathrm{m} \eta} \cos \phi_{\xi \eta} \sin \beta_{\xi},(9) \\
& \left. \pm r_{\mathrm{b} \eta} \cos \beta_{\xi}\right) \cdot\left(\boldsymbol{X}_{\xi}^{\mathrm{T}}, \boldsymbol{X}_{\eta}^{\mathrm{T}}\right)^{\mathrm{T}}+e_{\xi \eta}
\end{aligned}
$$

where $e_{\xi \eta}$ represents the STE of the mesh $\xi \eta$, and $k_{\xi \eta}$ is the corresponding mesh stiffness. $\beta_{\xi}$ denotes the helical angle. $\varphi_{\xi}=\alpha_{\xi \eta} \mp \phi_{\xi \eta}, \alpha_{\xi \eta}$ is the pressure angle, $\phi_{\xi \eta}$ is the position angle. $r_{\mathrm{m} \xi}$ and $r_{\mathrm{m} \eta}$ are the reference circle radii of Gear $\xi$ and $\eta$, respectively. $r_{\mathrm{b} \xi}$ and $r_{\mathrm{b} \eta}$ are the base circle radii of Gear $\xi$ and $\eta$, respectively. $X_{\xi}$ and $X_{\eta}$ are the vibration displacement vectors of Gear $\xi$ and $\eta$, respectively. For the symbol ' \pm ', the superscript is used when $\xi \eta=\mathrm{G} 1 \mathrm{G} 2$, and the subscript is available as $\xi \eta=\mathrm{G} 3 \mathrm{G} 4$. 


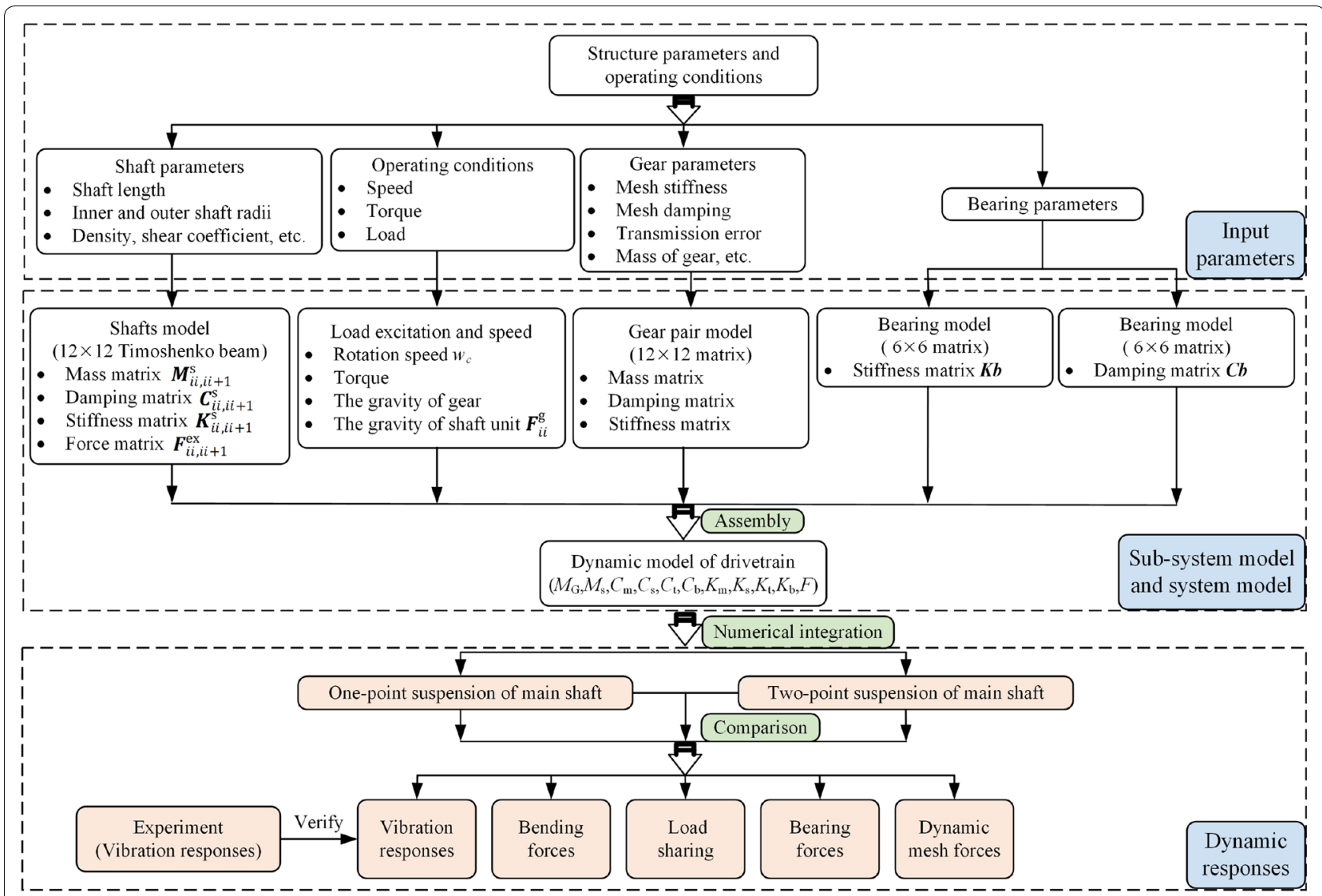

Figure 6 Flowchart of the proposed theoretical approach

For unconstrained generalized coordinates, the kinetic energy is

$$
T=\frac{1}{2}\left(\sum_{\chi=s, r, c, 1, \ldots, N, \mathrm{G} 1, \ldots, \mathrm{G} 4,20, \mathrm{gen}} \boldsymbol{X}_{\chi}^{\mathrm{T}} \boldsymbol{M}_{\chi} \boldsymbol{X}_{\chi}\right),
$$

and the potential energy is

$$
\begin{aligned}
& U=\frac{1}{2}\left(\sum_{i=1}^{N} k_{s p i} \Delta_{s p i}^{2}+k_{r p i} \Delta_{r p i}^{2}+k_{\mathrm{G} 1 \mathrm{G} 2} \Delta_{\mathrm{G} 1 \mathrm{G} 2}^{2}+k_{\mathrm{G} 3 \mathrm{G} 4} \Delta_{\mathrm{G} 3 \mathrm{G} 4}^{2}\right) \\
& +\frac{1}{2}\left(\sum_{l=s, r, c} \boldsymbol{X}_{l}^{\mathrm{T}} \boldsymbol{K} \boldsymbol{b}_{l} \boldsymbol{X}_{l}+\sum_{i=1}^{N} \Delta_{c p i}^{\mathrm{T}} \boldsymbol{K} \boldsymbol{b}_{i} \Delta_{c p i}\right) \\
& +\frac{1}{2}\left(\sum_{H=7,9,10}\left(\boldsymbol{X}_{H}^{\mathrm{s}}\right)^{\mathrm{T}} \boldsymbol{K} \boldsymbol{b}_{H} \boldsymbol{X}_{H}^{\mathrm{s}}\right) \\
& +\frac{1}{2}\left(\sum_{\substack{ \\
q=18, p=c \\
q=s, p=8 \\
q=17, p=21} \Delta_{q p}^{\mathrm{T}} \boldsymbol{k}_{q p} \Delta_{q p}}\right) .
\end{aligned}
$$

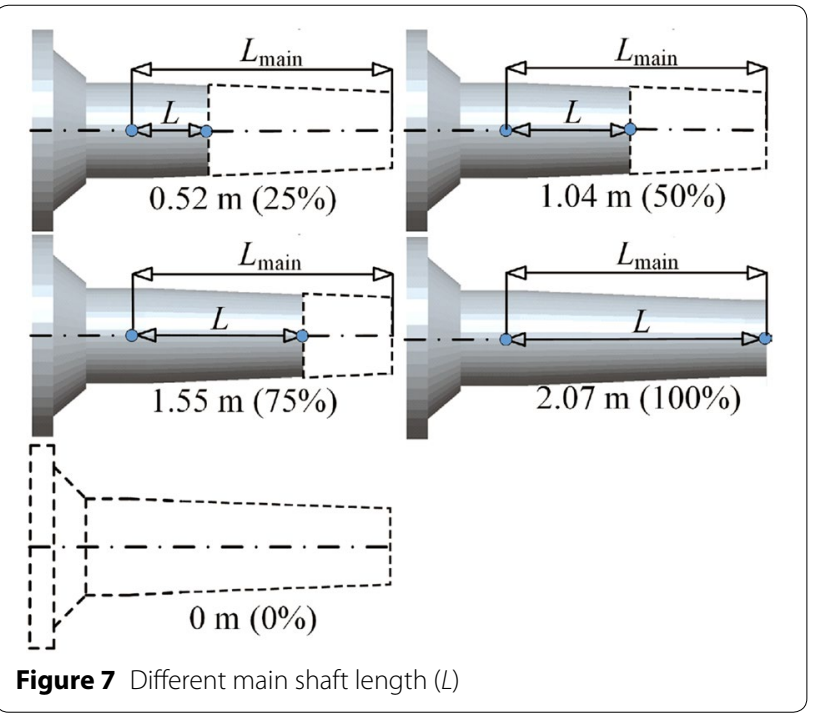

In Eq. (10a), $\boldsymbol{M}_{20}$ and $\boldsymbol{M}_{\text {gen }}$ represent the mass matrices of the impeller and generator, respectively. $\Delta_{c p i}$ denotes the deformation between carrier and the $i$ th planet gear [26]. $\Delta_{q p}$ is the connecting deformation matrix between 

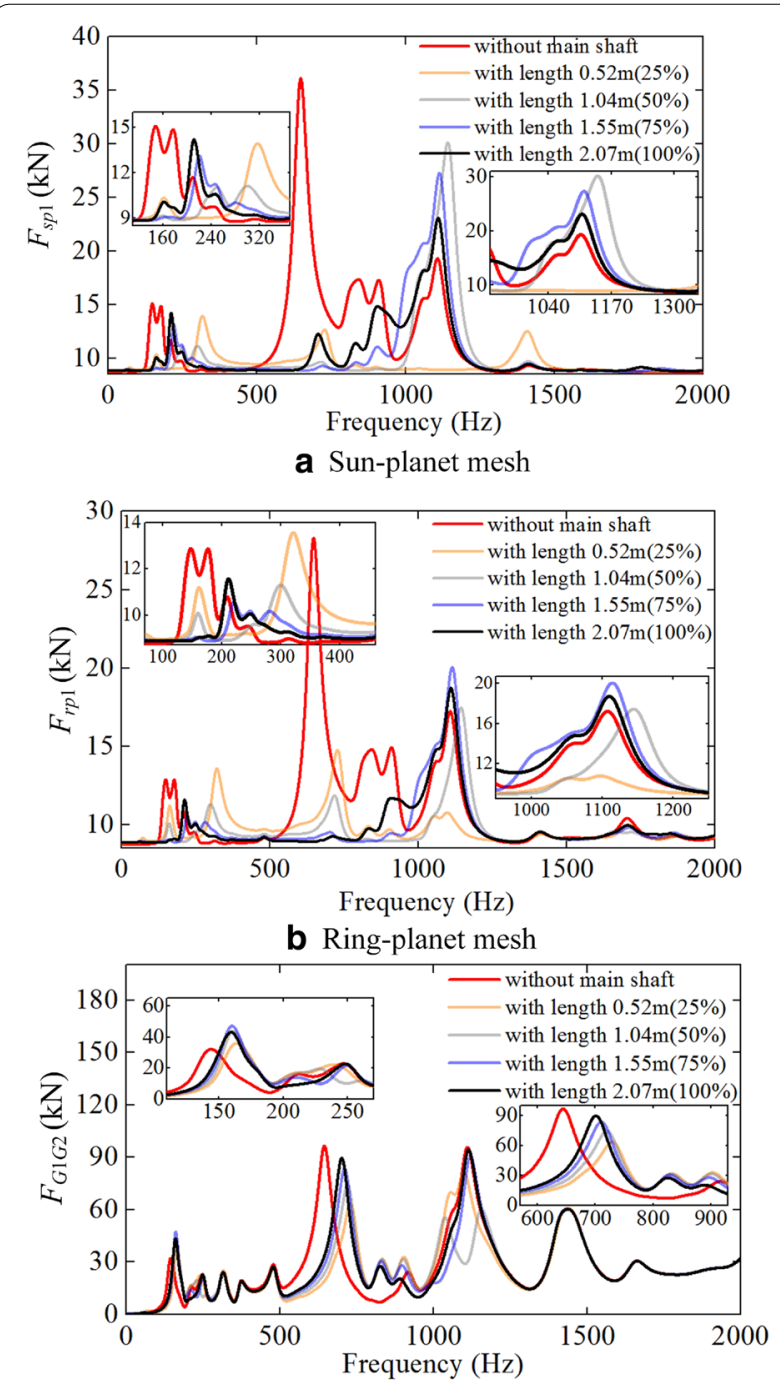

c Gear1-Gear2 mesh

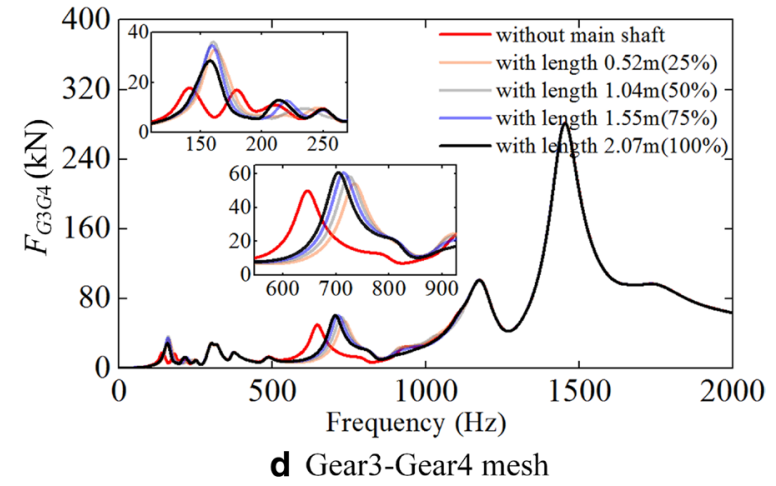

Figure 8 Dynamic mesh forces

the components $q$ and $p$, and $\boldsymbol{k}_{q p}$ denotes the connecting stiffness matrix [26].
After using the Lagrange energy method (Eq. (11)), the corresponding mass matrix $\left(\boldsymbol{M}_{\mathrm{G}}\right)$, mesh stiffness matrix $\left(\boldsymbol{K}_{\mathrm{m}}\right)$, bearing stiffness matrix $\left(\boldsymbol{K}_{\mathrm{b}}\right)$ and connecting stiffness matrix $\left(\boldsymbol{K}_{\mathrm{t}}\right)$ can be calculated.

$$
\frac{\mathrm{d}}{\mathrm{d} t} \frac{\partial L}{\partial \dot{\boldsymbol{X}}}-\frac{\partial L}{\partial \boldsymbol{X}}=\boldsymbol{Q}
$$

where $L=T-U$, and $Q$ is the generalized force including the applied torques and gravity of gears [27]. $X$ is the displacement vector of a drivetrain system.

Note, the form of mesh damping matrix $\left(\boldsymbol{C}_{\mathrm{m}}\right)$ is similar to mesh stiffness matrix $\left(\boldsymbol{K}_{\mathrm{m}}\right)$, in which the coefficient of mesh stiffness is replaced by corresponding mesh damping. Bearing damping matrix $\left(\boldsymbol{C}_{\mathrm{b}}\right)$ and connecting damping matrix $\left(\boldsymbol{C}_{\mathrm{t}}\right)$ are calculated by Rayleigh damping and empirical formula, respectively.

\subsection{Overall Model of Drivetrain}

Based on the analysis above, the displacement vector of a drivetrain system, which contains gears and flexible shaft elements, can be classified into a vector $\boldsymbol{X}$.

For one-point suspension of main shaft, the expression of $X$ is

$$
\begin{aligned}
\boldsymbol{X}= & \left(\boldsymbol{X}_{s}^{\mathrm{T}}, \boldsymbol{X}_{r}^{\mathrm{T}}, \boldsymbol{X}_{c}^{\mathrm{T}}, \boldsymbol{X}_{1}^{\mathrm{T}}, \ldots, \boldsymbol{X}_{N}^{\mathrm{T}}, \boldsymbol{X}_{7}^{\mathrm{T}}, \ldots,\right. \\
& \left.\boldsymbol{X}_{17}^{\mathrm{T}}, \boldsymbol{X}_{18}^{\mathrm{T}}, \ldots, \boldsymbol{X}_{20}^{\mathrm{T}}, \boldsymbol{X}_{\text {gen }}^{\mathrm{T}}\right)^{\mathrm{T}},
\end{aligned}
$$

and for two-point suspension of main shaft, the expression of $X$ is changed to be written as

$$
\begin{aligned}
\boldsymbol{X}= & \left(\boldsymbol{X}_{s}^{\mathrm{T}}, \boldsymbol{X}_{r}^{\mathrm{T}}, \boldsymbol{X}_{c}^{\mathrm{T}}, \boldsymbol{X}_{1}^{\mathrm{T}}, \ldots, \boldsymbol{X}_{N}^{\mathrm{T}}, \boldsymbol{X}_{7}^{\mathrm{T}}, \ldots,\right. \\
& \left.\boldsymbol{X}_{17}^{\mathrm{T}}, \boldsymbol{X}_{18}^{\mathrm{T}}, \ldots, \boldsymbol{X}_{20}^{\mathrm{T}}, \boldsymbol{X}_{21}^{\mathrm{T}}, \boldsymbol{X}_{\text {gen }}^{\mathrm{T}}\right)^{\mathrm{T}},
\end{aligned}
$$

where $\boldsymbol{X}_{g}$ denotes the vibration displacement vector of the component $g(g=s, r, c, 1, \ldots, N, 7, \ldots, 20$, or 21 , gen $)$ under its own local coordinate system.

Associating the lumped mass models of mesh with flexible shaft elements, equations of motion of the entire system can be organized as

$$
\begin{aligned}
& \left(\boldsymbol{M}_{\mathrm{G}}+\boldsymbol{M}_{\mathrm{s}}\right) \ddot{X}+\left(\boldsymbol{C}_{\mathrm{m}}+\boldsymbol{C}_{\mathrm{s}}+C_{\mathrm{t}}+\boldsymbol{C}_{\mathrm{b}}\right) \dot{X} \\
& \quad+\left(\boldsymbol{K}_{\mathrm{m}}+\boldsymbol{K}_{\mathrm{s}}+\boldsymbol{K}_{\mathrm{t}}+\boldsymbol{K}_{\mathrm{b}}\right) \boldsymbol{X}=\boldsymbol{F},
\end{aligned}
$$

where $\boldsymbol{M}_{\mathrm{s}}$ and $\boldsymbol{K}_{\mathrm{s}}$ are the mass and stiffness matrices of the flexible shafts. $\boldsymbol{C}_{\mathrm{s}}$ is the damping matrix of the flexible shafts. $\boldsymbol{F}=\left(\boldsymbol{F}_{s}, \ldots, \boldsymbol{F}_{\text {gen }}\right)^{\mathrm{T}}$ is the force matrix, including applied torque loads and the gravity excitation of component. 
In order to demonstrate the article frame more clearly, flowchart of the simulation is represented as shown in Figure 6, which consists of three parts. Firstly, the system parameters are obtained by commercial software. Secondly, the sub-system model is developed and then assembled into system model in order. Finally, the dynamic responses of drivetrain considering different length and suspension configurations of main shaft are evaluated, and the proposed model is verified by experiment.

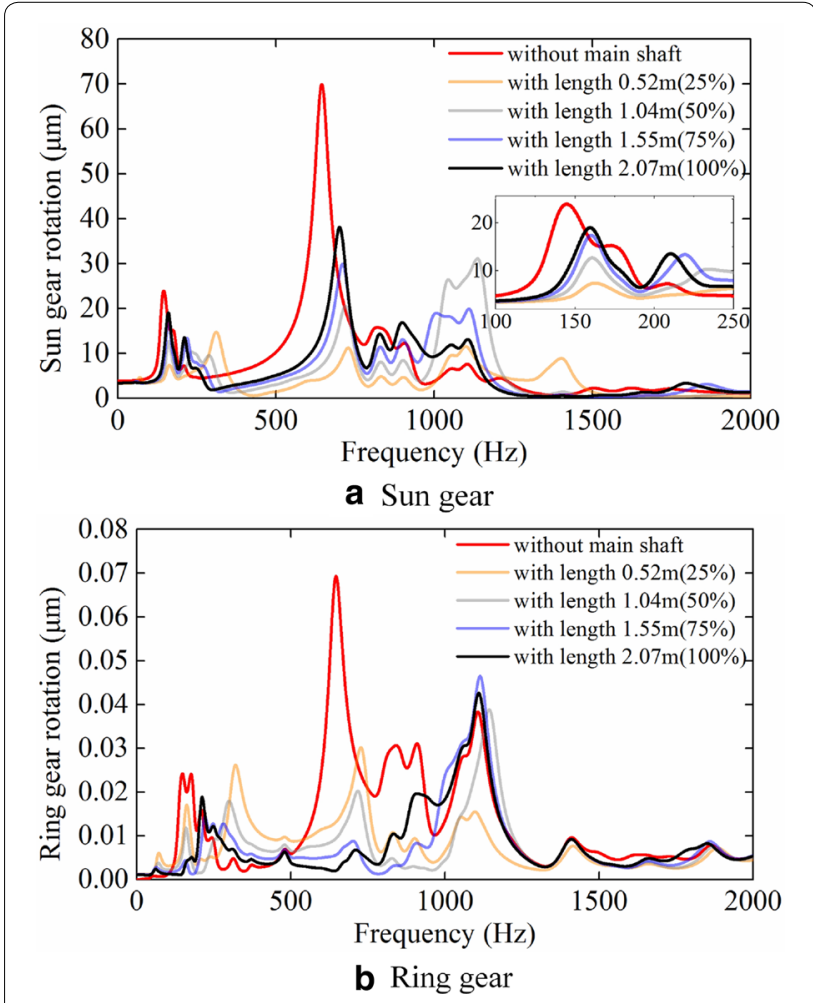

Figure 9 Dynamic torsional displacements

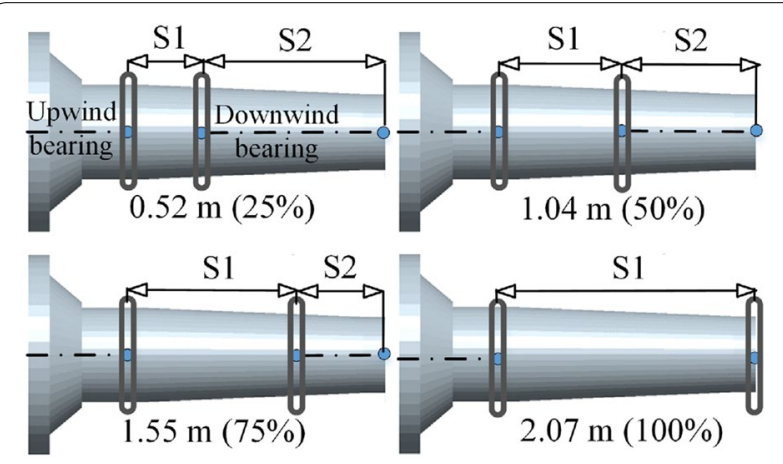

Figure 10 Different distance (S1) between two main bearings

\section{Numerical Analysis}

\subsection{Effects of Main Shaft Length on Dynamic Mesh Forces}

The flexible main shaft has a great influence on dynamic responses of gearbox [1]. Hence, the mesh frequency of the high-speed stage varies from $0 \mathrm{~Hz}$ to $2000 \mathrm{~Hz}$ to investigate the responses of dynamic mesh forces with different main shaft lengths, in which the excitations are mainly consisted of time-varying mesh stiffness and transmission error, etc. With one-point suspension of main shaft, the different main shaft length for comparison analysis is shown in Figure 7. The dynamic mesh forces in gearbox with different main shaft length under the rated input torque are shown in Figure 8. The dynamic torsional displacements of sun gear and ring gear with different main shaft length are shown in Figure 9.

As described in Figure 8, the coupling of flexible main shaft obviously shifts the partial excitation frequencies corresponding to response peaks in gearbox to higher frequencies in low-frequency range $(<1100 \mathrm{~Hz})$. At the planetary gear stage, the dynamic mesh force of sun-planet mesh has larger amplitude than ring-planet mesh, which is mainly caused by significant vibration amplitude of sun gear compared to ring gear as shown in Figure 9. As the increase of main shaft length, the partial frequency response peaks slightly decrease or increase but the corresponding frequencies obviously shift to lower range. It can increase the risks to generate resonance.

The amplitude of dynamic mesh forces in parallel gear stage is about one order of magnitude greater than that in low-speed stage due to the higher rotation speed, which can easily cause operating failure. The research on highspeed stage is becoming a hot issue [28]. Furthermore, studying on the dynamic responses in Figure 8, the 3rd gear stage is less influenced by the flexible main shaft compared to the 2nd gear stage while the most significant change occurs in planetary gear stage. This reveals that the gearbox has the ability to isolate loads between the individual gear stages.

\subsection{Effects of Suspension Configuration of Main Shaft on Dynamic Response at the Low-speed Stage}

As the aforementioned above, main shaft has a great effect on the dynamic responses of drivetrain, especially at the low-speed stage. Meanwhile, as another suspension configuration of main shaft shown in Figure 10, two-bearing configuration is usually applied in drivetrain being with four-point suspension to support the main shaft of drivetrain at the gearbox side. In order to differentiate these two configurations for further optimization, the comparisons of load distribution in each component 


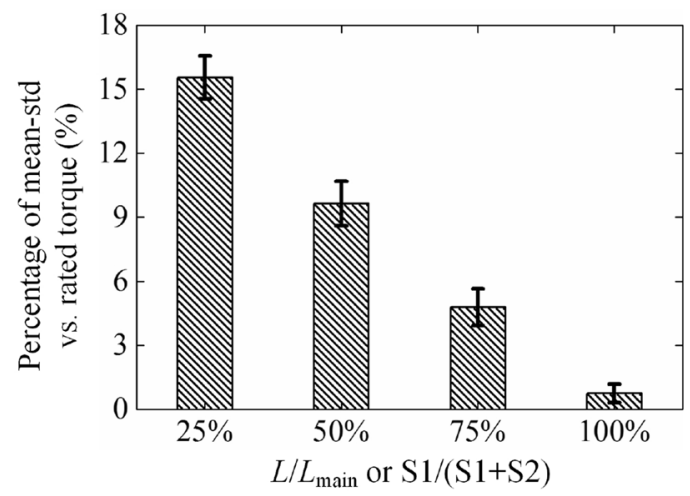

a One-point suspension

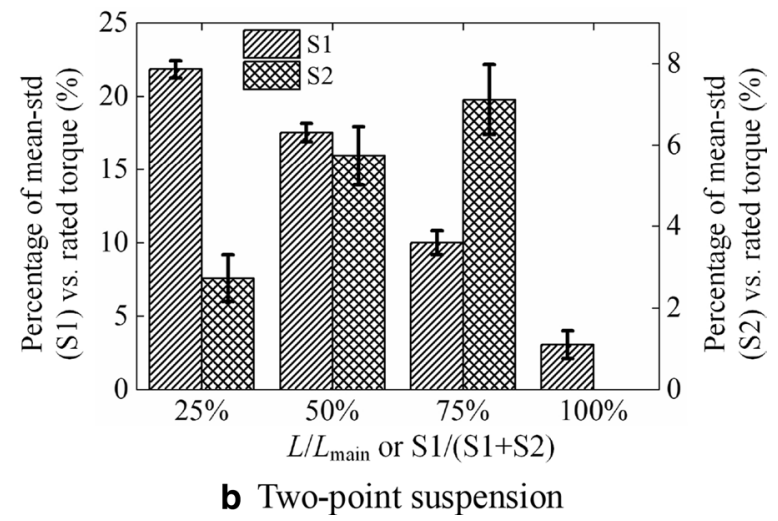

Figure 11 Main shaft bending forces in two suspension configurations

at the low-speed stage are investigated under the rated operating condition. Note, for two-point suspension configuration of main shaft, both bearings are assumed to have the same supporting stiffness for better investigating the difference caused by distance $\mathrm{S} 1$ between two main bearings, as shown in Figure 10 .

As shown in Figure 11, the main shaft bending forces in two suspension configurations are obtained and compared. Also, the radial forces of main shaft bearing in two suspension configurations are calculated in Figure 12. Meanwhile, the loads in carrier bearing and planet bearing are illustrated in Figures 13 and 14, respectively.

Results in Figures 11, 12 and 13 show that two suspension configurations of main shaft can remarkably affect the load distribution of component in the low-speed stage. As shown in Figure 11a, the bending force of main shaft, including mean value and standard deviation, is significantly decreased with the increase of main shaft length $(L)$, while the mean value of bearing force of main shaft is nearly linear increase, as presented in Figure 12a. For two-point suspension of main shaft as shown in Figures $11 \mathrm{~b}$ and $12 \mathrm{~b}$, the bending force of main shaft unit
(S2) and bearing force of main shaft (downwind), which are closer to gearbox, are obviously smaller than the loads in main shaft unit (S1) and main shaft bearing (upwind), respectively. It needs to notice that this suspension configuration would cause severely unbalanced loads in main shaft, leading to greater load concentrated in upwind part of main shaft. This means that the diameter of upwind main shaft unit S1 should be larger than downwind main shaft unit S2 as well as the upwind bearing supporting stiffness. As shown in Figure 13, the comparisons of carrier bearing load indicate that two-point suspension of main shaft is more beneficial to decrease carrier bearing load compared to the one-point suspension. This benefit significantly reflects in radial force and tilting force, which coincides with Figures 11 and 12.

Comparing with one-point suspension of main shaft, two-point suspension of main shaft can greatly inhibit the load fluctuation especially the tilting force of planet bearing, as shown in Figure 14. This result is similar to the standard deviation of bending force of main shaft shown in Figure 11. However, the mean value of the radial force and tilting force keeps constant due to the large force at planet bearing preloaded by sun-planet and ring-planet meshes [29].

In addition, the comparisons of dynamic mesh force at individual transmission stage are carried out by percentage differences between two suspension configurations. The first one is the one-point suspension of main shaft $(100 \%)$, and the second one is the two-point suspension of main shaft with different distance S1:

$$
\% \text { difference }=\frac{X_{\text {two }}-X_{\text {one }}}{X_{\text {one }}} \times 100 \%,
$$

where $X_{\text {one }}$ and $X_{\text {two }}$ denote the percentage of response value in the 1st and the 2 nd suspension configurations of main shaft, respectively.

As shown in Table 2, there are no obvious improvements in dynamic mesh forces, but the standard deviation is primarily influenced by different distance S1 associated with the low-speed stage, which agrees with Figure 14. Simultaneously, the results in Table 2 also indicate that the gearbox has the ability to isolate loads from planetary gear stage to parallel gear stage.

As a whole, a proper choice of length $(L)$ and distance (S1) of main shaft should depend on both the loads in main shaft and internal responses in gearbox for load balance among components, especially at the low-speed stage. Therefore, it is strongly meaningful in engineering to optimize structure parameter and suspension configuration of main shaft. 


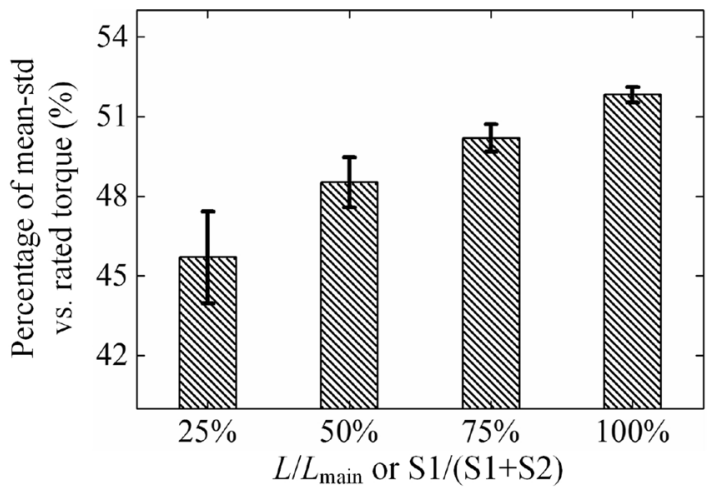

a One-point suspension

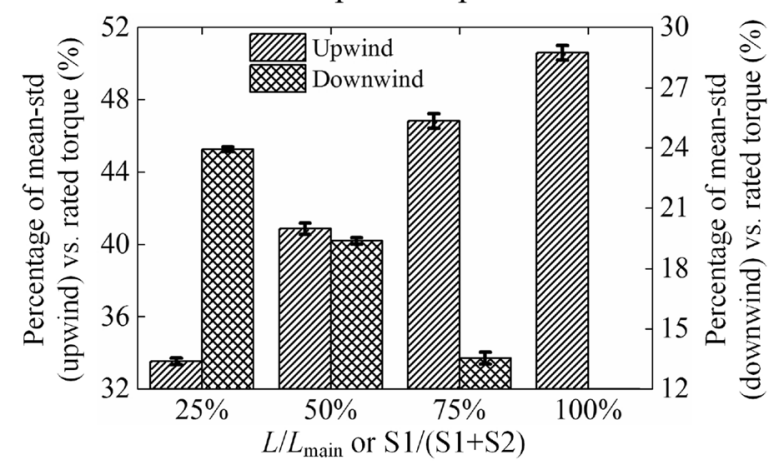

b Two-point suspension

Figure 12 The radial force of main shaft bearing

\subsection{Comparisons of Load Sharing and Carrier Bearing Force between Two Suspension Configurations}

As mentioned above, both the length and suspension configuration of main shaft are crucial to isolate the load fluctuation in gearbox. Therefore, the load sharing is conducted to comprehensively investigate those influences at planetary gear stage, as shown in Figure 15.

Results in Figure 15 show that the load sharing is remarkably influenced by main shaft length with onepoint suspension of main shaft, but this influence can be alleviated in two-point suspension of main shaft. Moreover, the load sharing factor in two suspension configurations decreases with the increase of the load. The dynamic model without main shaft is also validated by experiment [30].

The carrier bearing suffers heavy load and is sensitive to the coupled effects of main shaft, as shown in Figure 13. When the percentage of distance S1 between two main bearings is equal to $25 \%$, the force condition of carrier bearing is greatly improved compared to the one with one-point suspension (100\%). Thus, for further investigation of this advantage, the radial force and vibration displacement of carrier bearing are compared in three cases in a carrier cycle under the rated operating condition, as shown in Figure 16. In the response, the frequency corresponding to the mesh frequency is removed because it is minor and impairs for clarity of figure.

For the one-point suspension of main shaft (100\%), the maximum value (M_Max(I)) and the minimum value (M_Min(I)) of carrier bearing greatly increase compared to without main shaft (0\%), especially in gravitational direction ( $Y$-direction), which agrees with Eq. (4) and Figure 13. Fortunately, with the two-point suspension of main shaft (25\%), the maximum value (M_Max(II)) and the minimum value (M_Min(II)) of carrier bearing is significantly decreased. Moreover, the maximum value occurs when two planets move above the horizontal axis ( $X$-direction) simultaneously and the phase for these two planets is nearly symmetric along vertical axis ( $Y$-direction), which is nearly antisymmetric to the phase occurring the minimum value.

\section{Model Verification}

A wind field test for megawatt level wind turbine drivetrain was carried out to verify the simulated results. A remote real-time measurement system for wind turbine was established by SKF WindCon [31], and the principle of measurement system was shown in Figure 17. The acceleration sensors were utilized to measure the

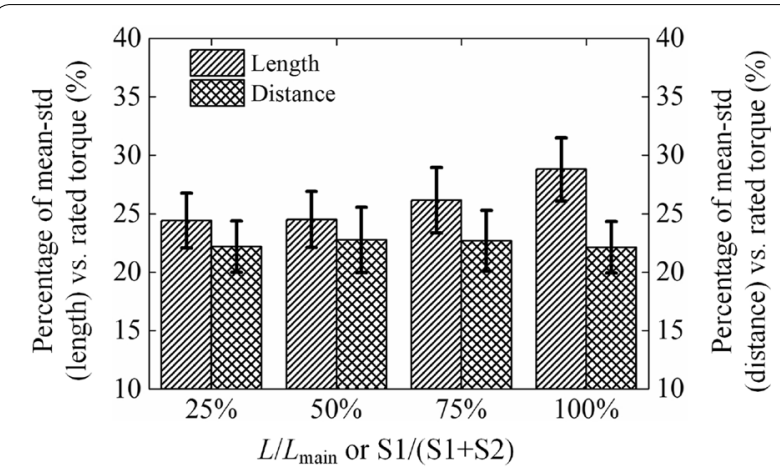

a Radial force

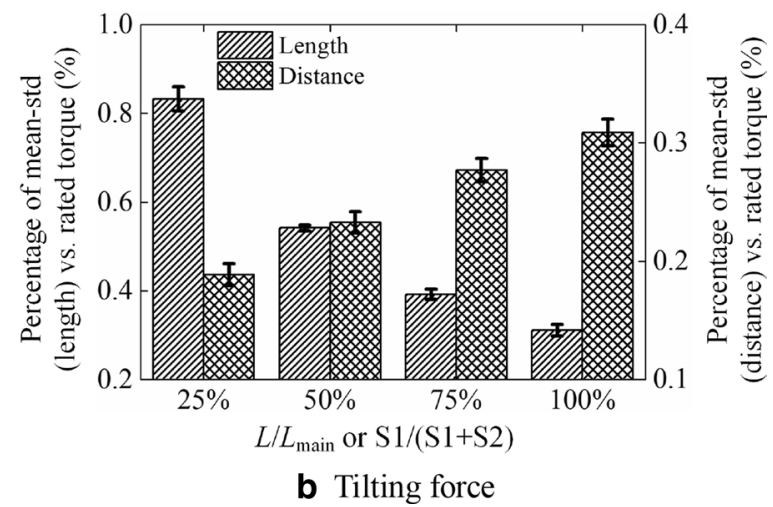

Figure 13 Carrier bearing forces in two suspension configurations 


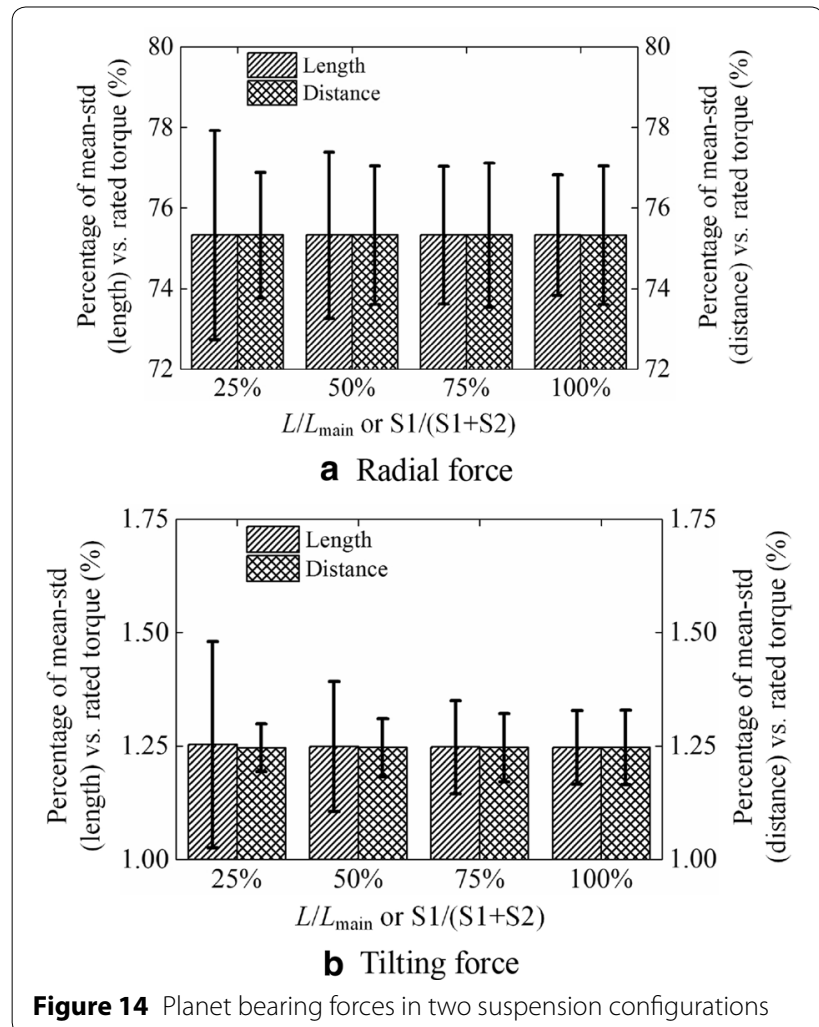

vibration of main shaft bearing and downwind bearing of high-speed stage and were installed on the gearbox housing as shown in Figure 17c, d, respectively. The sampling rate was about $2000 \mathrm{~Hz}$, and the generator was working in rated operation (about $1800 \mathrm{r} / \mathrm{min}$ ).

Note, for the main shaft only the load excitations, including input torque and the weight of impeller and main shaft, are considered in simulation. Therefore, only the vibration of main shaft bearing in vertical direction $(Y)$ is adopted as shown in Figure 18. In the downwind bearing of high-speed shaft the vibrations in horizontal direction $(X)$, vertical direction $(Y)$ and axial direction $(Z)$ were measured, which were represented in Figure 19.
These two measuring points correspond to the nodes which are labeled 'measuring point' as shown in Figures 3 and 5 , respectively.

From the results in Figures 18 and 19, the systematic vibration energy mainly concentrates in the mesh frequencies and their harmonic frequencies of the 2nd stage (fmi, $i=1,2, \ldots)$ and high-speed stage $(f h i, i=1,2, \ldots)$ for both experimental and simulated results. The simulated vibration magnitude of main shaft bearing is significantly less than experiment due to the neglect of load fluctuation at main shaft side. However, the main frequency characteristics, including the mesh frequencies and their harmonic frequencies of the parallel gear stages, can be observed in proposed model. This means the inversion of power flow transmission from high-speed stage to low-speed stage. In high-speed stage, because of the high rotation speed leading to larger mesh excitation, the mesh frequencies and their harmonic frequencies (fmi, fhi, $i=1,2, . .$, ) are dominant, which coincides with experiment.

Some testing errors still exist between the simulation and experiment, because there occurs many sideband frequencies in the vibration accelerations of main shaft and high-speed shaft bearings. It is mainly caused by the load fluctuation, bearing roller vibrations, errors and environmental noise, etc. All factors mentioned above are difficult to be considered accurately at present, thus, the dynamic model of drivetrain needs further improvement. However, according to the comparison analysis mentioned above, the experimental and simulated results are correlated reasonably in predicting the major peak position and general trends.

\section{Conclusions}

(1) A dynamic modeling approach for wind turbine drivetrain is proposed and a three-dimensional dynamic model of drivetrain is developed using the lumped parameter method. The detailed factors are considered, including the time-varying mesh

Table 2 Comparisons of dynamic mesh forces under the rated operating condition

\begin{tabular}{|c|c|c|c|c|c|c|c|c|c|c|c|c|}
\hline \multirow[b]{3}{*}{ Distance (m) } & \multicolumn{12}{|c|}{ Difference between two-point suspension configuration and one-point suspension configuration (100\%) } \\
\hline & \multicolumn{4}{|l|}{ Max } & \multicolumn{4}{|c|}{ Mean } & \multicolumn{4}{|l|}{ Std } \\
\hline & 0.52 & 1.04 & 1.55 & 2.07 & 0.52 & 1.04 & 1.55 & 2.07 & 0.52 & 1.04 & 1.55 & 2.07 \\
\hline \multicolumn{13}{|l|}{ Gear pair (\%) } \\
\hline Sun-planet & 0.13 & 0.49 & 0.63 & 0.50 & 0 & 0 & 0 & 0 & 2.49 & 11.06 & 15.30 & 11.45 \\
\hline Ring-planet & 0.16 & 0.51 & 0.64 & 0.51 & 0 & 0 & 0 & 0 & 2.44 & 10.75 & 14.84 & 11.10 \\
\hline Gear 1-Gear 2 & 0 & 0 & 0 & 0 & 0 & 0 & 0 & 0 & 0.02 & 0.02 & 0.02 & 0.01 \\
\hline Gear 3-Gear 4 & 0 & 0 & 0 & 0 & 0 & 0 & 0 & 0 & 0 & 0.01 & 0.02 & -0.01 \\
\hline
\end{tabular}




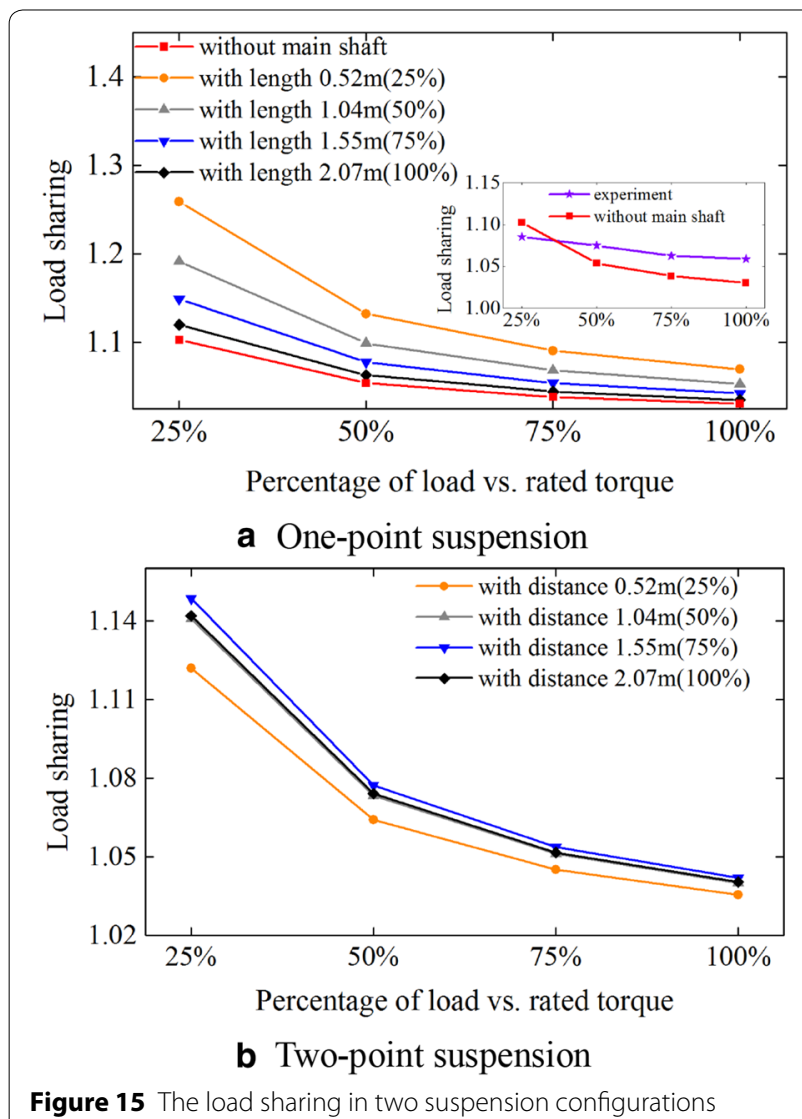

Figure 15 The load sharing in two suspension configurations

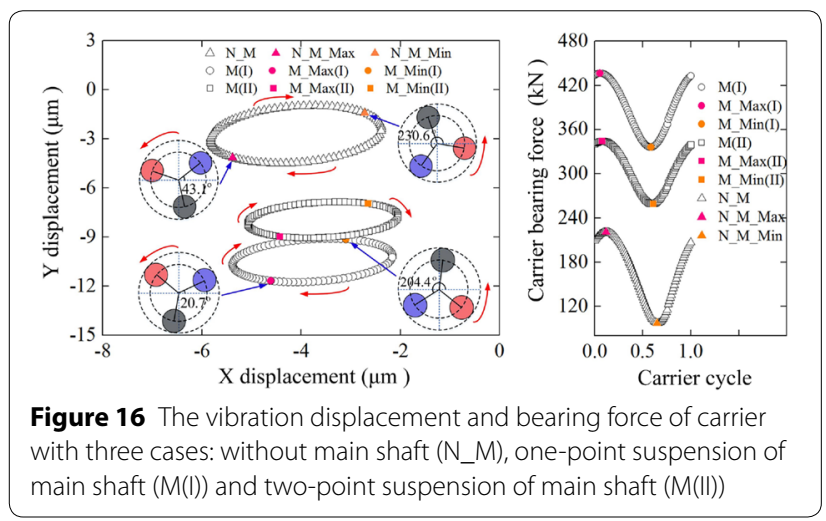

stiffness and transmission error, gravity excitation, flexible shafts and suspension configuration of main shaft, etc.

(2) Considering the main shaft obviously shifts partial resonance frequencies, especially at the lowspeed stage, to higher frequency range compared to gearbox without main shaft, but the resonance frequencies tend to decrease towards lower frequency range as the increase of main shaft length.

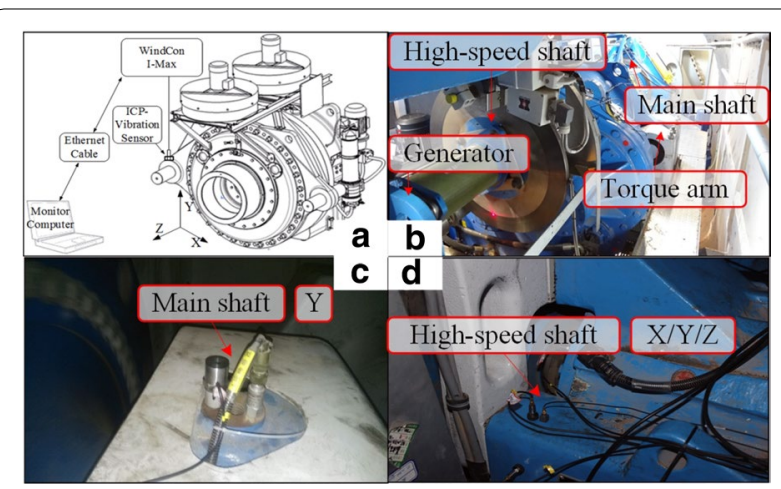

Figure 17 Experiment of drivetrain in wind field: a test principles, $\mathbf{b}$ installation of sensors, $\mathbf{c}$ measuring point of main shaft bearing and $\mathbf{d}$ measuring point of downwind bearing of high-speed shaft
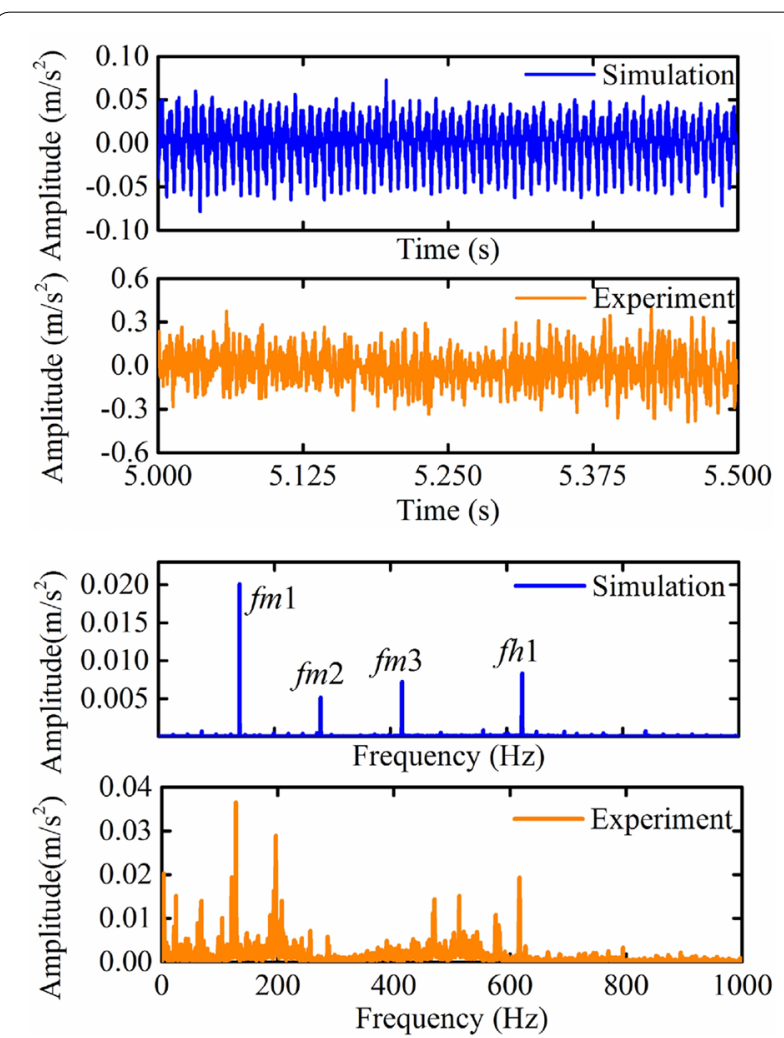

Figure 18 Vibration acceleration of main shaft in time domain and frequency domain

Properly increasing main shaft length is effective to decrease the bending force of main shaft, however, it could increase the bearing load of main shaft and carrier. Hence, the load sharing is further disrupted by main shaft, but this effect could be alleviated by increasing torque load. 

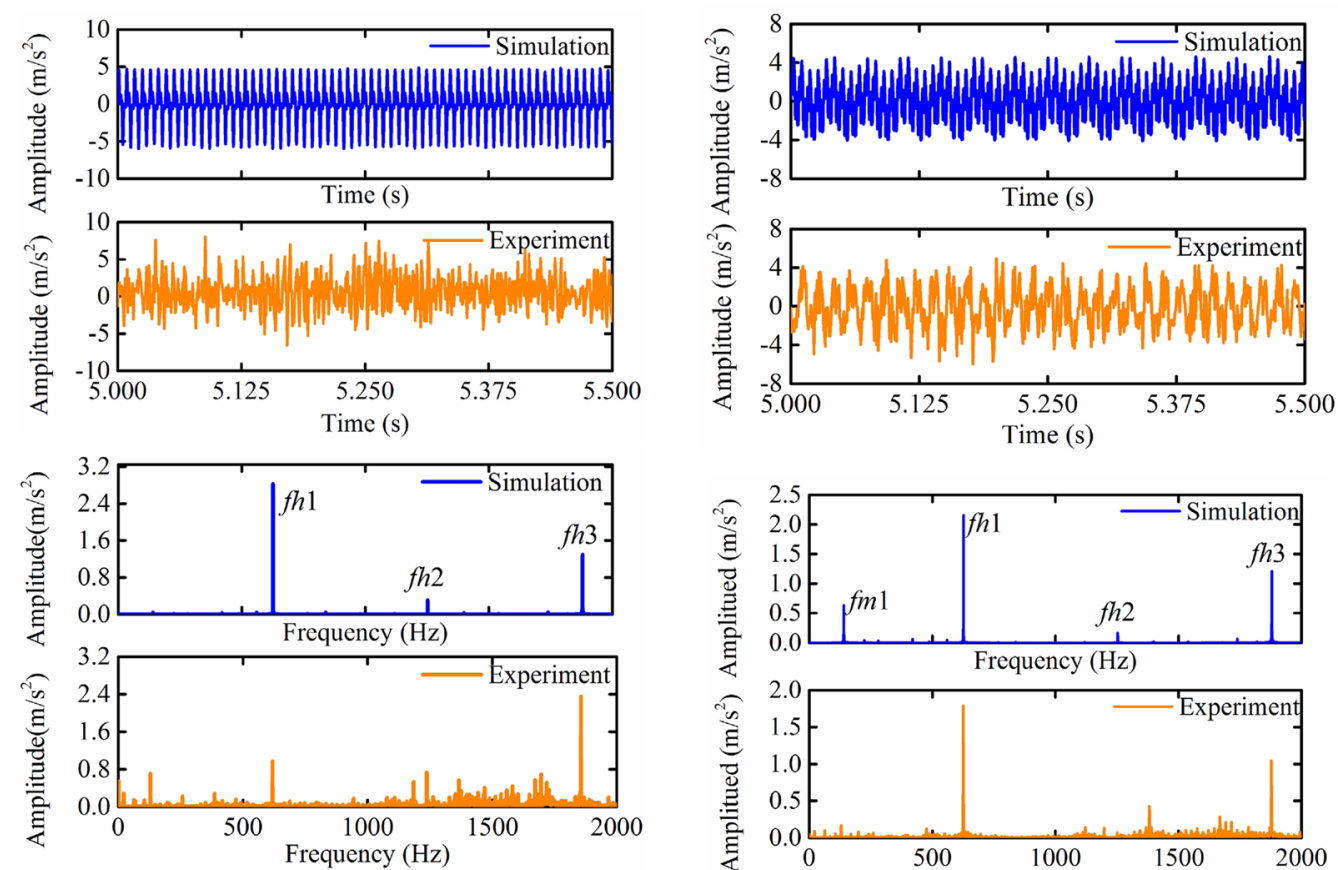

a $X$-direction
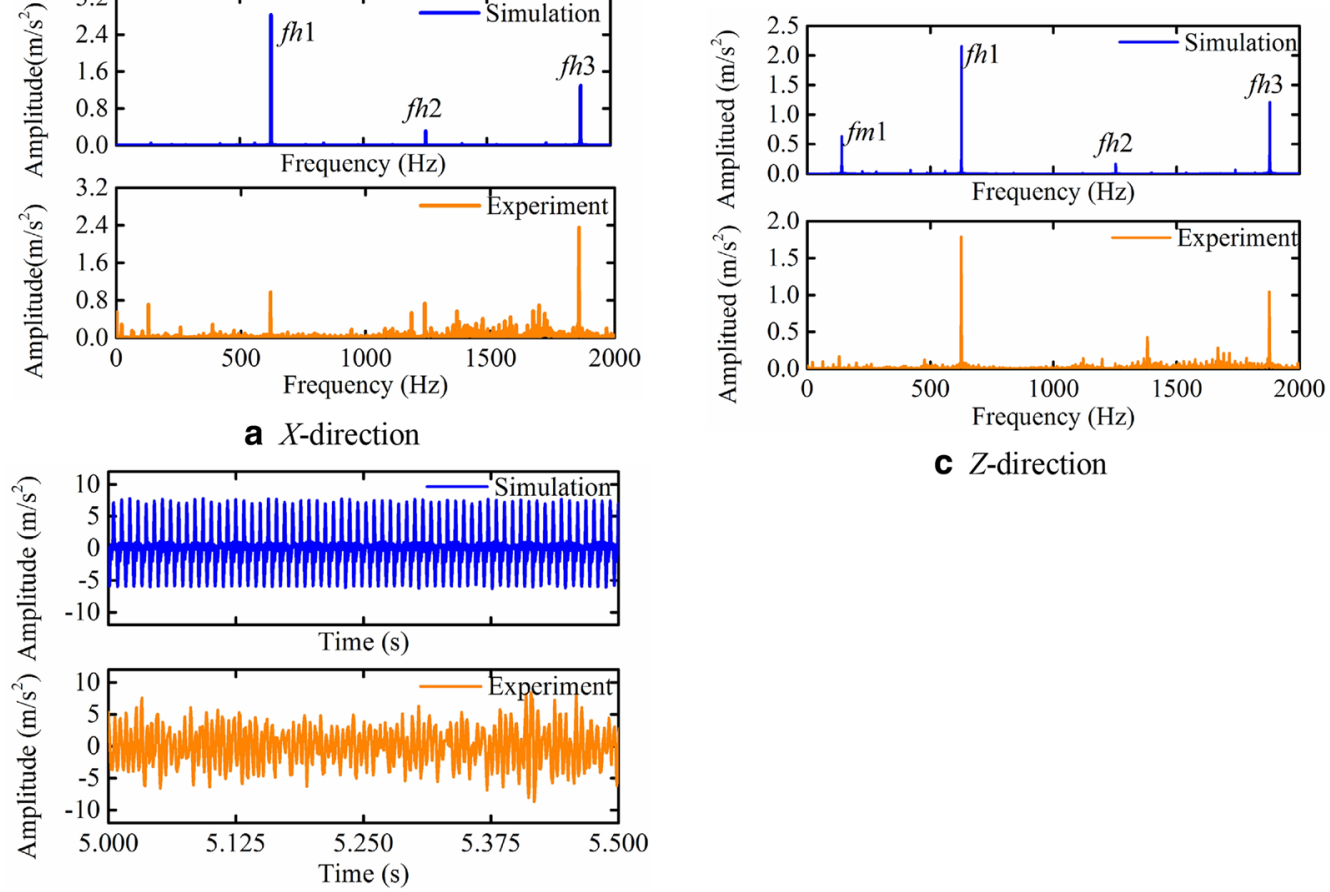

c Z-direction

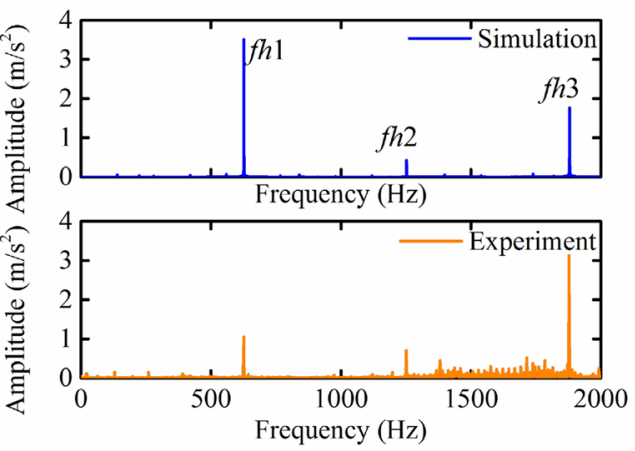

b $Y$-direction

Figure 19 Vibration acceleration of downwind bearing of high-speed shaft in time domain and frequency domain

(3) Comparing to the one-point suspension of main shaft, two-point suspension configuration has more superiority to inhibit the load at the lowspeed stage. Furthermore, the appropriate distance between two main bearings is a critical factor to balance the load distribution at the low-speed stage. However, this configuration could cause larger load in upwind main bearing than downwind, which 
means the main shaft diameter at upwind position must be increased as well as the corresponding bearing stiffness.

(4) An experimental remote real-time system is developed to evaluate the vibration performance of drivetrain in the wind field. The main excitations are consisted of mesh frequencies and their harmonic frequencies of parallel gear stages. Also, the obvious inversion of power flow transmission from highspeed stage to low-speed stage could be observed at main shaft bearing. As a whole, the simulated results correlate with experiment reasonably in predicting the major peak position and general trends.

\section{Authors' Contributions}

JT wrote the manuscript; CZ was in charge of the whole trial; CS assisted with writing and analysis; $\mathrm{HH}$ assisted with technique check; $\mathrm{YL}$ assisted with the experiment. All authors read and approved the final manuscript.

\section{Author Details}

${ }^{1}$ The State Key Laboratory of Mechanical Transmissions, Chongqing University, Chongqing 400044, China. ${ }^{2}$ CSIC (Chongqing) Haizhuang Windpower Equipment Co., Ltd, Chongqing 401122, China.

\section{Authors' Information}

Jianjun Tan, born in 1991, is currently a PhD candidate at State Key Laboratory of Mechanical Transmissions, Chongqing University, China. His research area is dynamic analysis of wind turbine drivetrain.

Caichao Zhu, born in 1967, is currently a professor at State Key Laboratory of Mechanical Transmissions, Chongqing University, China. His research fields include the dynamics of gear systems, the tribology of mechanical transmissions, and the design of accurate transmission.

Chaosheng Song, born in 1983, is currently a professor at State Key Laboratory of Mechanical Transmissions, Chongaing University, China. His research fields include the dynamics of crossed beveloid gears.

Huali Han, born in 1980, is currently a senior engineer at CSIC (Chongqing) Haizhuang Wind power Equipment Co., Ltd, China. Her research area is system technology of wind turbine.

Yao Li, born in 1989, is currently a PhD candidate at State Key Laboratory of Mechanical Transmissions, Chongqing University, China. His research area is reliability analysis of wind turbine.

\section{Competing Interests}

The authors declare that they have no competing interests.

\section{Funding}

Supported by National Natural Science Foundation of China (Grant Nos. 51775061, 51575061) and Chongqing Municipal Research Program of Frontier and Application Foundation of China (Grant No. cstc2018jcyjAX0087).

\section{Received: 9 November 2017 Accepted: 1 April 2019}

Published online: 18 April 2019

\section{References}

[1] Y Guo, J Keller, La Cava W, et al. Recommendations on model fidelity for wind turbine gearbox simulations. United States: National Renewable Energy Lab, Golden, CO, 2015.

[2] J Helsen, P Peeters, K Vanslambrouck, et al. The dynamic behavior induced by different wind turbine gearbox suspension methods assessed by means of the flexible multibody technique. Renewable Energy, 2014, 69: 336-346.
[3] J Helsen, F Vanhollebeke, F D Coninck, et al. Insights in wind turbine drive train dynamics gathered by validating advanced models on a newly developed 13.2 MW dynamically controlled test-rig. Mechatronics, 2011, 21(4): 737-752.

[4] J Helsen, F Vanhollebeke, B Marrant, et al. Multibody modelling of varying complexity for modal behavior analysis of wind turbine gearboxes. Renewable Energy, 2011, 36(11): 3098-3113.

[5] J Peeters, D Vandepitte, P Sas. Multibody simulation of a three-stage planetary gearbox in a wind turbine. Proceedings of the 7th German Wind Energy Conference, German, 2004.

[6] J L Peeters, D Vandepitte, P Sas. Analysis of internal drive train dynamics in a wind turbine. Wind Energy, 2006, 9(1-2): 141-161.

[7] Y Guo, J Keller, W Lacava. Combined effects of gravity, bending moment, bearing clearance, and input torque on wind turbine planetary gear load sharing. AGMA Fall Technical Meeting, Dearborn, USA, 2012.

[8] R Schkoda, A Bibo, Y Guo, et al. Characterizing the influence of abstraction in full-scale wind turbine nacelle testing. ASME 2016 International Design Engineering Technical Conferences and Computers and Information in Engineering Conference, USA, 2016.

[9] C C Zhu, S Chen, C S Song, et al. Dynamic analysis of a megawatt wind turbine drive train. Journal of Mechanical Science and Technology, 2015, 29(5): 1913-1919.

[10] C C Zhu, S Chen, H J Liu, et al. Dynamic analysis of the drive train of a wind turbine based upon the measured load spectrum. Journal of Mechanical Science and Technology, 2014, 28(6): 2033-2040.

[11] S L Zhang, C C Zhu, C S Song, et al. Natural characteristic analysis of wind turbine drivetrain considering flexible supporting. Proceedings of the Institution of Mechanical Engineers, Part C: Journal of Mechanical Engineering Science, 2017: 0954406217692006.

[12] V K Ambarisha, R G Parker. Nonlinear dynamics of planetary gears using analytical and finite element models. Journal of Sound and Vibration, 2007 302(3): 577-595.

[13] T M Ericson, R G Parker. Planetary gear modal vibration experiments and correlation against lumped-parameter and finite element models. Journal of Sound and Vibration, 2013, 332(9): 2350-2375.

[14] W Shi, CW Kim, C W Chung, et al. Dynamic modeling and analysis of a wind turbine drivetrain using the torsional dynamic model. International Journal of Precision Engineering \& Manufacturing, 2013, 14(1): 153-159.

[15] M Zhao, J C Ji. Nonlinear torsional vibrations of a wind turbine gearbox. Applied Mathematical Modelling, 2015, 39(16): 4928-4950.

[16] P Srikanth, A S Sekhar. Wind turbine drive train dynamic characterization using vibration and torque signals. Mechanism \& Machine Theory, 2016, 98: 2-20.

[17] S Wei, Q Han, Z Peng, et al. Dynamic analysis of parametrically excited system under uncertainties and multi-frequency excitations. Mechanical Systems \& Signal Processing, 2016, 72: 762-784.

[18] C C Zhu, XY Xu, H J Liu, et al. Research on dynamical characteristics of wind turbine gearboxes with flexible pins. Renewable Energy, 2014, 68: 724-732.

[19] C C Zhu, XY Xu, T C Lim, et al. Effect of flexible pin on the dynamic behaviors of wind turbine planetary gear drives. Proceedings of the Institution of Mechanical Engineers, Part C: Journal of Mechanical Engineering Science, 2013, 227(1): 74-86.

[20] H F Zhai, C C Zhu, C S Song, et al. Dynamic modeling and analysis for transmission system of high-power wind turbine gearbox. Journal of Mechanical Science and Technology, 2015, 29(10): 4073-4082.

[21] Y Xing, M Karimirad, T Moan. Modelling and analysis of floating spar-type wind turbine drivetrain. Wind Energy, 2014, 17(4): 565-587.

[22] L Sethuraman, Y Guo, S Sheng. Main bearing dynamics in three-point suspension drivetrains for wind turbines. American Wind Energy Association Conference \& Exhibition, USA, 2015.

[23] X Liang. Dynamic characteristics research based on load spectrum of megawatt level wind turbine gearbox. Chongqing: Chongqing University, 2013. (in Chinese)

[24] J S Rao, T N Shiau, J R Chang. Theoretical analysis of lateral response due to torsional excitation of geared rotors. Mechanism \& Machine Theory, 1998, 33(6): 761-783.

[25] ZX Fei. Research on finite element modeling and dynamic behaviors of complex multi-rotor coupled systems. Hangzhou: Zhejiang University, 2013. (in Chinese) 
[26] J J Tan, C C Zhu, C C Song, et al. Study on the dynamic modeling and natural characteristics of wind turbine drivetrain considering electromagnetic stiffness. Mechanism and Machine Theory, 2019, 134: 541-561.

[27] Y Guo, R G Parker. Dynamic modeling and analysis of a spur planetary gear involving tooth wedging and bearing clearance nonlinearity. European Journal of Mechanics-A/Solids, 2010, 29(6): 1022-1033.

[28] J A Keller, Y Guo, L Sethuraman. Gearbox reliability collaborative investigation of gearbox motion and high-speed-shaft loads, United States: National Renewable Energy Lab, Golden, CO, 2016.

[29] Y Guo, R G Parker. Dynamic analysis of planetary gears with bearing clearance. Journal of Computational \& Nonlinear Dynamics, 2012, 7(4): 041002.
[30] S S Wang. Research on dynamic characteristics of wind power transmission system considering non-torque loads. Chongqing: Chongqing University, 2017. (in Chinese)

[31] SKF: WindCon by SKF condition monitoring for wind turbine systems, [2019-03-13].https://www.skf.com/group/industry-solutions/wind-energ y/applications/index.html.

\section{Submit your manuscript to a SpringerOpen ${ }^{\circ}$ journal and benefit from:}

- Convenient online submission

- Rigorous peer review

- Open access: articles freely available online

- High visibility within the field

- Retaining the copyright to your article

Submit your next manuscript at $\boldsymbol{\nabla}$ springeropen.com 